\title{
Improved 2D slice-interleaved flow-independent cardiac black blood imaging using Ferumoxytol
}

Junfei $\mathrm{Lu}^{1 *}$, Paul J Finn ${ }^{2}$, Peng $\mathrm{Hu}^{2}$

From 18th Annual SCMR Scientific Sessions

Nice, France. 4-7 February 2015

\section{Background}

Double inversion recovery (DIR) is the most commonly used black blood (BB) preparation method. However its single slice nature makes the acquisition inefficient and flow-dependence causes insufficient blood suppression when stagnant blood or in-plane blood flow is present. In this work, we propose to use ferumoxytol, an FDA approved iron oxide particle for treating iron deficiency anemia, as an MR contrast agent to achieve flow-independent $\mathrm{BB}$ imaging by taking advantage of its strong

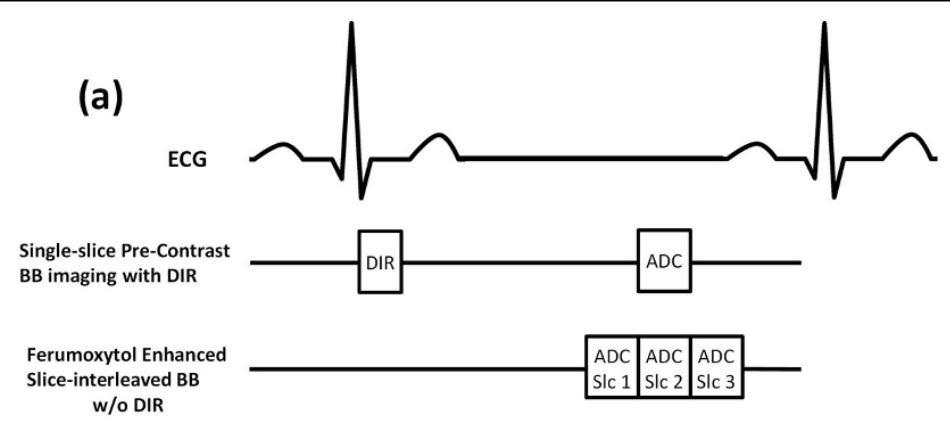

(b)

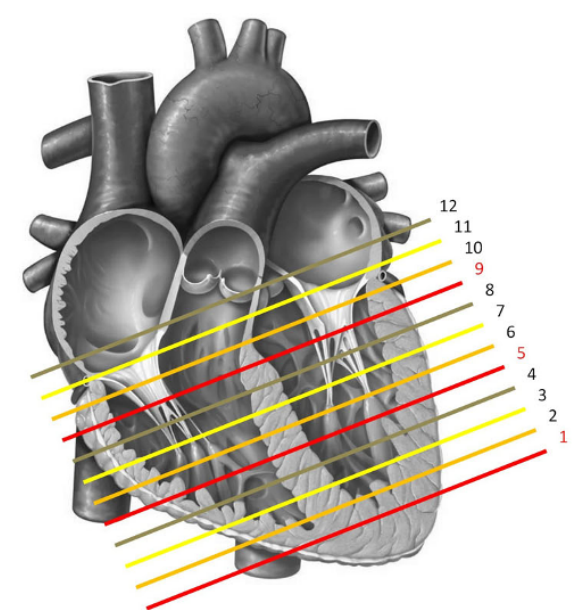

Figure 1 (a) Block diagrams for single-slice DIR TSE and slice-interleaved TSE without DIR. The removal of DIR pulses enable interleaved slice acquisition. The central ADC of the interleaved acquisition is located at the same cardiac phase as ADC in single slice scheme. (b) In traditional DIR BB imaging, 12 short axis slices are acquired sequentially one slice in each scan. While in the slice-interleaved mode, 3 slices with $300 \%$ slice distance are grouped into one interleaved acquisition. For example slice\# 1,5,9 (marked in red) are acquired in one scan.

$\overline{1}$ Bioengineering, University of California, Los Angeles, Los Angeles, CA, USA

Full list of author information is available at the end of the article

(c) 2015 Lu et al; licensee BioMed Central Ltd. This is an Open Access article distributed under the terms of the Creative Commons 
R2 relaxivity. As our technique eliminates the need for DIR preparation, we propose to achieve higher scan efficiency by interleaving the imaging slices.

\section{Methods}

On seven healthy volunteers, we acquired 12 consecutive short axis (SA) slices covering the ventricles and 2 horizontal long axis (HLA) slices, both pre- and postferumoxytol injection. Conventional ECG gated singleslice breath-held DIR Turbo Spin Echo (TSE) sequence was used for pre-contrast acquisition, with $T R=2 R-R$ interval, $\mathrm{TE}=37 \mathrm{~ms}$, echo spacing $(\mathrm{ESP})=5.25 \mathrm{~ms}$, echo train length $(E T L)=15$ and $T I=600 \mathrm{~ms}$. Subsequently, ferumoxytol was injected $(4 \mathrm{mg}-\mathrm{Fe} / \mathrm{kg})$ and the proposed BB imaging shown in Fig. 1 was performed. The elimination of DIR preparation enabled slice-interleaved scan where $12 \mathrm{SA}$ slices were acquired in 4 breath-holds. TR, TE, ESP and ETL were kept the same for the post-contrast sequence. A TE of $37 \mathrm{~ms}$ was found to be a good balance between suppressing blood signal and maintaining myocardium signal. SNR, CNR and sharpness of the septal wall were quantified and compared using the preand post-contrast $\mathrm{BB}$ techniques.

\section{Results}

In mid-ventricle SA slices (slice number 7-12), both preand post- contrast images offered satisfactory dark blood contrast. For apical slices (slice number 1-6), post-contrast images showed significant improvement in all 7 volunteers by eliminating stagnant blood signal. In HLA views (shown in Fig. 2), the stagnant blood was evident in pre-contrast images near apex and mid-ventricle myocardium; whereas in post-contrast images, such residual blood signals were eliminated in all volunteers. Average myocardial SNR and myocardium-blood CNR increased after ferumoxytol injection, especially for apical segments (CNR: $6.2 \pm 8.13$ vs. $22.6 \pm 6.4 \mathrm{~s}, \mathrm{P}<0.0001$ ). The pre- and post-contrast $\mathrm{BB}$ imaging had similar sharpness values $(\mathrm{P}=0.877)$.

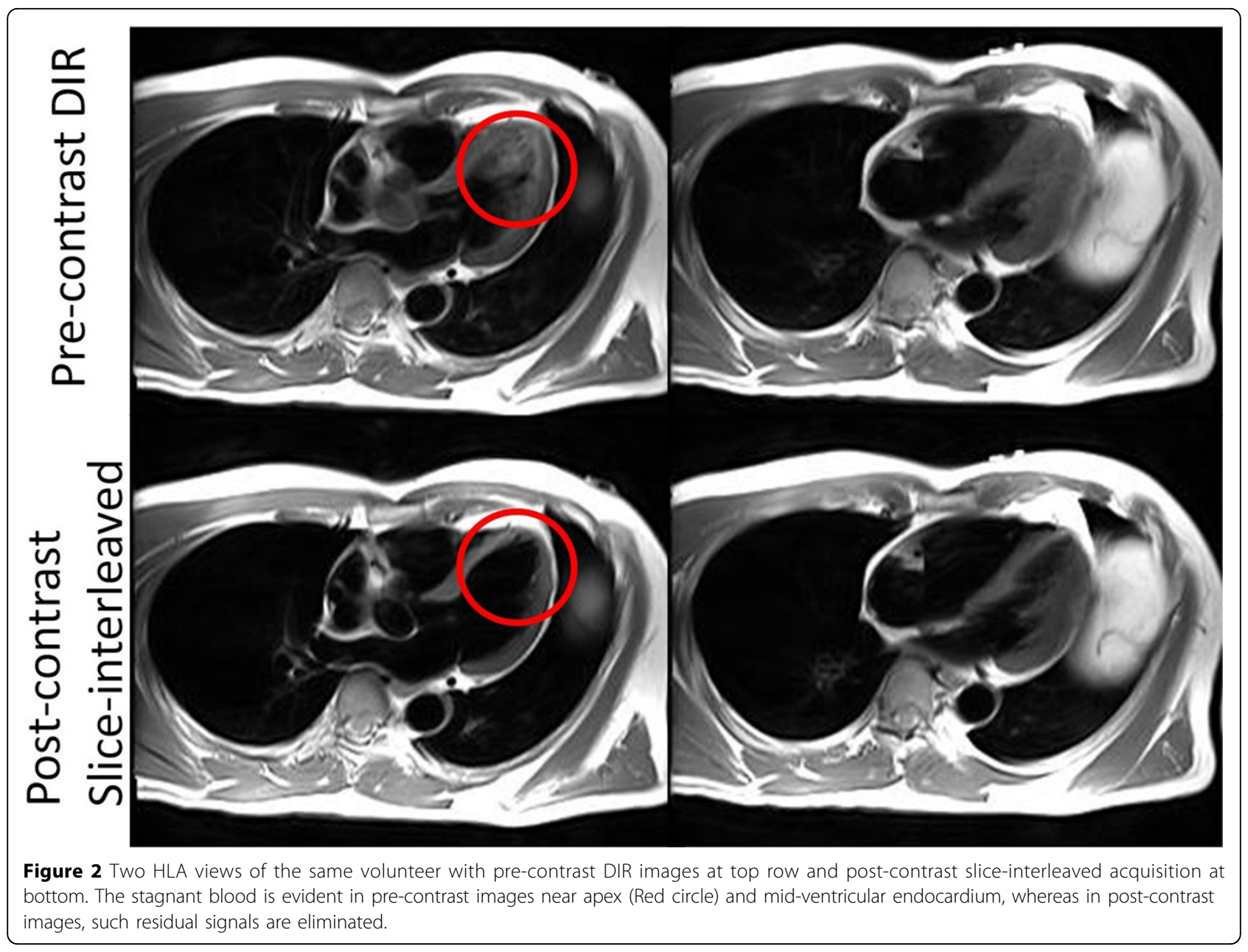




\section{Conclusions}

Compared to conventional DIR BB imaging, the proposed ferumoxytol-enhanced slice-interleaved TSE technique provides improved blood signal suppression that does not depend on flow and is at least $3 \mathrm{X}$ faster than conventional DIR for the same anatomical coverage. It also provides higher SNR and CNR due to signal boost from ferumoxytol.

\section{Funding}

N/A.

\section{Authors' details}

${ }^{1}$ Bioengineering, University of California, Los Angeles, Los Angeles, CA, USA.

${ }^{2}$ Radiology, University of California, Los Angeles, Los Angeles, CA, USA.

Published: 3 February 2015

- Convenient online submission

- Thorough peer review

- No space constraints or color figure charges

- Immediate publication on acceptance

- Inclusion in PubMed, CAS, Scopus and Google Scholar

- Research which is freely available for redistribution 